\title{
No-Shows in outpatient medical institutions in Germany - A pilot study about explanations of patients why they missed their appointment
}

\author{
Wolfgang Frank ${ }^{1}$, Erich Kasten ${ }^{2}$ \\ ${ }^{1}$ Practice for Neurology and Psychiatry, Luebecker Str. 20, D-23611 Bad Schwartau, Germany \\ ${ }^{2}$ Medical School Hamburg, University of Applied Science, Am Kaiserkai 1, D-20457 Hamburg, Germany
}

Email addresses:

neurofrank@dgn.de (W. Frank), erikasten@aol.com (E. Kasten)

To cite this article:

Wolfgang Frank, Erich Kasten. No-Shows in Outpatient Medical Institutions in Germany - A Pilot Study about Explanations of Patients Why they Missed their Appointment. Science Journal of Public Health. Vol. 2, No. 3, 2014, pp. 238-242.

doi: $10.11648 /$ j.sjph.20140203.27

\begin{abstract}
Patients, who miss an appointment in medical institutions (so called "no-shows") cause a significant damage to the health care system. We asked 181 patients (65\% female, $35 \%$ male; average age 43.7 y.) how often they missed appointments in the past 12 months. The questionnaire's reliability was $r=0.76$. We recorded 2,778 events. $3.13 \%$ of the appointment were missed and $0.43 \%$ came much too late. Most common reasons were forgetfulness and confusion of dates. Severity of pain and health-limitations correlated positive with punctuality. Among the no-shows were significantly more unemployed subjects than people with an occupation. There was no significant difference between pensioners and unemployed participants. Only $25 \%$ found memory aids such as letters, phone calls or short text messages helpful before the appointment. $60 \%$ of patients agreed to pay a fee of max. 1.- $€$ for such a service. As charge for doctor's loss of income due to the missed appointment a payment between 10.- $€$ and 20.- $€$ was judged to be appropriate. Two groups of "persons of risk" have been identified: 1 . non-working people and 2. patients with poor memory. Both groups valued reminders for the appointment positively.
\end{abstract}

Keywords: No-Shows, Appointments, Missed Appointments, Reminders

\section{Introduction}

In health care system facilities it often happens that appointments are missed by patients. In Anglo-American terms these are called „No-Shows“. Practitioners and therapists suffer financial losses if they cannot compensate these No-Shows out of the waiting room. For patients who missed their appointment, necessary examinations and treatments can therefore not be provided [1, 10, 17]. Later they often have to be interlaced between other patient's appointments. „No-Shows” obstruct the regular working hours and other patients cannot be provided with an appointment in a timely manner. Most probably additional costs occur for idling staff and facilities [4].

American hospitals see up to $42 \%$ No-Shows $[7,19,20]$. Patients missing their appointments more likely young and socioeconomic deprived; best predictor was prior timeliness $[1,11]$. Most of them quoted ,forgetfulness" as the main reason in addition to psychosocial problems, disappearance of health problems in the meantime or, in contrast, emergency access to hospitals due to worsening, urgent workplace requirements, child minding, public transport problems, exceeded waiting time until the appointment $[1,2$, $5,18]$. Lacey et al. [13] distinguished emotional reasons, staff rudeness and lack of understanding for schedule systems. Patient's treatment fees increased the number of no-shows with lower socio-economic state [25].

Various solutions have been provided, mostly reminders shortly in advance prior the appointment $[1,3,6,8,9,15,18$, $20,22]$. Short messaging was of minor success due to costs [16] and Satiani et al. [23] found that the reminded group often missed the appointment nonetheless. In other studies transport facilities were organized, self-management education was provided, changes in scheduling systems arranged, foreshortening of waiting time, in-time rewards or no-show sanctioning as well as overbooking of appointments 1, 6, [24]. Combined methods showed quotes below $10 \%$ [12]. 
In Germany currently no studies exist in outpatient medical facilities towards the „No-Show"-problem. Therefore this small pilot study asked for patient's reasons for not coming and what they regard as helpful reminders for punctuality.

\section{Methods}

In a hypothesis-conducted cross-sectional study patients were interviewed with a self developed questionnaire. The participants were informed to return the questionnaire with their consent and their anonymous answers were scientifically analyzed. Reference period for the contacts with physicians were the past 12 months. The questionnaires were laid out in the waiting rooms of 6 doctors respectively therapists in the vicinity of the town of Luebeck (Germany) and the patients were asked to complete the questionnaire and drop it into a sealed box. Most of the questions were to be answered in a five-step range. Statistical analysis was predominantly done by nonparametric statistical methods (e.g. U-test, Spearman's correlation coefficient). In principle the median coefficient should have been calculated, but the median is known for „swallowing“ minor differences, therefore we decided for the arithmetic average \pm standard deviation.

Inclusion criteria: All adults with a minimum of one appointment in the medical system during the last 12 months. Exclusion criteria: (1) No doctor's/therapist's appointment during the last 12 months. (2) Implausible filled questionnaires. (3) Too much missing data $(>10 \%$ or no statement about the targeted variables 'missed appointments' and 'delays'). (4) Not matching reliability questions (see below).

The ethical committee of The University of Luebeck had no objections (Ref.-No.: 09-103).

\section{Results}

\subsection{Sample}

In total 185 persons filled out the questionnaire, four samples had to be dismissed on behalf of too many missing items. To verify the reliability of answers, two items with quite similar contents have been submitted on two different locations of the questionnaire, one of them with reversed polarity. The Pearson's correlation coefficients were Rho= -0.761 , resp. $\mathrm{R}=-0.756(\mathrm{p}<0.01)$. The data had been proved consistent after scrutinizing every single patient, i.e. no data set had to be rejected. In addition, the statements were checked for consistency (e.g. male visits with an obstetrician, severity of pain not in accordance to the illness, accordance of the number of appointments with the number of the different medical faculties and others). Even with rigid application of these criteria, no further data-set had to be dismissed. 181 questionnaires were evaluable.

The two groups (with/without missed appointments) did not vary significantly in relation to gender $\left(\mathrm{Chi}^{2}=0.82\right.$, $\mathrm{p}=0.22$ ) and age (t-test: $\mathrm{p}=0.22$ ) (see table 1). In total the collective group had had 2,779 appointments with a doctor or therapist in the reference period. Included were $87(3,13 \%)$ no shows and $12(0,43 \%)$ severe delays ( $>1 \mathrm{~h}$.). 126 patients $(69,6 \%)$ declared, never having forgotten an appointment. $39(21,5 \%)$ missed once, $11(6,1 \%)$ twice, $2(1,1 \%)$ three times, $1(0.6 \%)$ four times and $2(1,2 \%)$ more than four times. $6(3.3 \%)$ patients admitted to have been unpunctual, $1(0,6 \%)$ twice and another one four times (0,6\%). 123 stated no missing and no delayed appointments.

Table 1. Description of the sample

\begin{tabular}{llll}
\hline & Total $(\mathrm{n}=\mathbf{1 8 1})$ & Group without missed app. $(\mathrm{n}=\mathbf{1 2 3})$ & Group with missed app. / delays $(\mathrm{n}=\mathbf{5 8})$ \\
\hline Gender & & & \\
Male & $35,4 \%(\mathrm{n}=64)$ & $37,4 \%(\mathrm{n}=46)$ & $31,0 \%(\mathrm{n}=18)$ \\
Female & $63,5 \%(\mathrm{n}=115)$ & $61,8 \%(\mathrm{n}=76)$ & $67,2 \%(\mathrm{n}=39)$ \\
No Statement & $1,1 \%(\mathrm{n}=2)$ & $0,8 \%(\mathrm{n}=1)$ & $1,8 \%(\mathrm{n}=1)$ \\
Average Age $( \pm \mathrm{SD})$ & $43,7 \pm 16,5 \mathrm{y}$. & $43,4 \pm 17,1 \mathrm{y}$. & $44,4 \pm 15,2 \mathrm{y}$. \\
Average Appointments $( \pm \mathrm{SD})$ & $17,8 \pm 23,3$ & $15,6 \pm 18,1$ & $23,1 \pm 32,3$ \\
\hline
\end{tabular}

The doctors/therapists visited within the survey period were: General Practitioner (74.6\%), Dentist (64.1\%), Neurologist (35.4\%), Obstetricians (35.4\%), Ophthalmologist (32.6\%), Orthopedic Specialist (29.3\%), Psychiatrist (28.7\%), Physiotherapist $(23.8 \%)$, Dermatologist $\quad(23.2 \%)$, Psychotherapist (23.2\%), ENT Specialist (21.5\%), Internist (17.7\%), Surgeon (16.6\%), Cardiologist (13.8\%), Radiologist (11.0\%), Occupational Therapist (6.1\%), Endocrinologists (5.5\%), Urologist (5.5\%), Company Doctor (5.0\%), Pulmonary Specialist (5.0\%), Occupational Physician (1.7\%), Speech and Language Therapist (1.1\%), Human Geneticist $(0.6 \%)$, others.

Forgetfulness was the main reason for missing an appointment, see fig. 1 for detailed causes.

\subsection{Detailed Results}

The first hypothesis inspects the context between severity of illness and missing of an appointment. The Mann-Whithney U-Test delivered significant differences between the groups without/with missed appointments (limitations due to illness: $3.26 \pm 1.26$ vs. $2.61 \pm 1.17, Z=-3.299, p=0.001^{* *}$; seriousness of illness: $3.47 \pm 1.24$ vs. $\left.3.08 \pm 1.01, Z=-2.096, p=0.036^{*}\right)$, i.e. patients without missed appointments estimated to be more restricted by their illness and felt more pain. Spearman's correlation coefficient between this restrictions and the number of missed appointments is $\mathrm{R}=-0.256\left(\mathrm{p}=0.01^{* *}\right)$; between intensity of pain and missed appointments $\mathrm{R}=-0.153$ $(p=0.053$, trend), i.e. the more restrictions of every-day life the less missed appointments. 


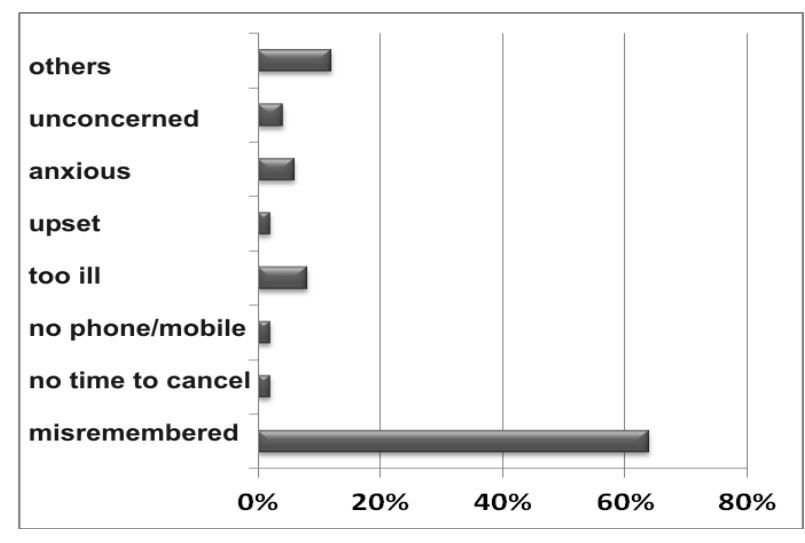

Figure 1. Reasons for missed appointments

The second hypothesis compared the connection between frequency of rendezvous in the medical system and failed meetings. The group with missed appointments/delays showed a higher number of dates (average $15.6 \pm 18.1$ vs. $23.1 \pm 32.3$; t-test $\mathrm{p}=0.054$, trend). The Pearson's correlation coefficient was $r=0.15(\mathrm{p}=0.07$, trend).

Hypothesis $\mathrm{H}_{4}$ tested gender differences. Results prove that women missed their appointments less frequently than men $(0.44 \pm 0.74$ vs. $0.56 \pm 1.53)$ but were delayed slightly more often $(0.07 \pm 0.41$ vs. $0.06 \pm 0.30$, both n.s.).

Hypothesis $\mathrm{H}_{4}$ examined the impact of age. The correlation coefficient between age and missed appointments was $r=0.11$ ( $\mathrm{p}=0.17$, n.s.), i.e. there is no significant difference between younger and older patients.

Hypothesis $\mathrm{H}_{5}$ checked for differences between employed $(n=105)$ and unemployed patients $(n=39)$. There was only a trend in respect to the amount of missed appointments (employed $0.34 \pm 0.63$, retiree/unemployed $0.92 \pm 1.89$, $\mathrm{p}=0.056$ ), but a significant difference within the delayed meetings (employed 0.05 \pm 0.40 , retiree/unemployed $0.18 \pm 0.45, \mathrm{p}=0.002 * *)$. Unemployed patients (a) and retirees (b) did not differ significantly: (a) $1.11 \pm 1.96$ missed appointments and $0.22 \pm 0.44$ delays and (b) $0.87 \pm 1.90$ missed appointments and $0.17 \pm 0.46$ delays.

Hypothesis H6 explored self esteem of memory capacity. Spearman's Rho between judgment of own memory performance and occurrence of missed appointments amounts to $\mathrm{R}=0.25\left(\mathrm{p}=0.001^{* *}\right)$, as well as between own judgment of recollection and missed appointments $\mathrm{R}=0.23$ $\left(p=0.002^{* *}\right)$. Frequency of missed work-related and personal dates correlated significantly with missed appointments in the health care system $(\mathrm{R}=0.26, \mathrm{p}=0.001 * *$ resp. $\mathrm{R}=0.25, \mathrm{p}=0.001 * *)$. Patients who have a tendency to forget their appointments in the outpatient medical systems rate their memory-capacity as poor and forgot other appointments, too.

Hypothesis $\mathrm{H} 7$ evaluated whether patients with forgotten scheduling would accept reminders rather than people without missed appointments. Questioned was the helpfulness of a written reminder, a phone call or a short message (SMS).
Table 2. Frequency of answers regarding reminders

\begin{tabular}{llll}
\hline & $\begin{array}{l}\text { Letter of } \\
\text { Reminder }\end{array}$ & Phone Call & SMS \\
\hline $\begin{array}{l}\text { No, not } \\
\text { Rather not }\end{array}$ & $27.6 \%(\mathrm{n}=59)$ & $33.7 \%(\mathrm{n}=61)$ & $37.0 \%(\mathrm{n}=67)$ \\
Neither/nor & $12.7 \%(\mathrm{n}=49)$ & $27.6 \%(\mathrm{n}=50)$ & $13.8 \%(\mathrm{n}=25)$ \\
$\begin{array}{l}\text { Rather yes } \\
\text { Yes, much so }\end{array}$ & $19.9 \%(\mathrm{n}=36)$ & $20.4 \%(\mathrm{n}=19)$ & $11.0 \%(\mathrm{n}=20)$ \\
$\begin{array}{l}\text { No comment no } \\
\text { mobile }\end{array}$ & $1.1 \%(\mathrm{n}=2)$ & $1.1 \%(\mathrm{n}=2)$ & $16.0 \%(\mathrm{n}=29)$ \\
\hline
\end{tabular}

There was certain reluctance towards reminders as shown in Tab. 2. About $60 \%$ of interviewees did not want them, about $10 \%$ are indifferent and only $25 \%$ of them regarded them as helpful. A closer data analysis between patients with / without failed appointments revealed, that the group with forgotten dates found reminders rather helpful (see Tab. 3).

Exploratory evaluated was the level of acceptance fees for not showing up. Tab 4. lists the rate of alternatives. Noticeable is that only $6.5 \%$ in the failing category marked "amount of real loss", whereas $19.4 \%$ of the punctually patients agreed to accept such a fee (U-Test: $p=0.09 ; \mathrm{Z}=$ -1.69).

Table 3. Discrimination of study participants with/without failed appointments to the three questions of reminders.

\begin{tabular}{|c|c|c|c|}
\hline & $\begin{array}{l}\text { No missed } \\
\text { appointment } \\
(n=123)\end{array}$ & $\begin{array}{l}\text { Missed } \\
\text { appointment } \\
(n=56)\end{array}$ & $\begin{array}{l}\text { Mann-Whithey } \\
\text { U-Test }\end{array}$ \\
\hline $\begin{array}{l}\text { Letter of } \\
\text { Reminder }\end{array}$ & $2.09 \pm 1.11$ & $3.09 \pm 1.46$ & $\begin{array}{l}Z=-4.31 \\
p=0.001 * *\end{array}$ \\
\hline Phone Call & $2.16 \pm 1.21$ & $2.87 \pm 1.44$ & $\begin{array}{l}\mathrm{Z}=-3.15 \\
\mathrm{p}=0.002 * *\end{array}$ \\
\hline SMS & $2.71 \pm 1.44$ & $3.50 \pm 1.62$ & $\begin{array}{l}\mathrm{Z}=-2.94 \\
\mathrm{p}=0.003 * *\end{array}$ \\
\hline
\end{tabular}

Table 4. Acceptance for fees for missed appointments.

\begin{tabular}{|c|c|c|c|}
\hline & $\begin{array}{l}\text { Total } \\
(n=159)\end{array}$ & $\begin{array}{l}\text { Without } \\
\text { missing } \\
(n=113)\end{array}$ & $\begin{array}{l}\text { With missing } \\
\text { resp. delay } \\
(n=46)\end{array}$ \\
\hline $\begin{array}{l}\text { Fees not } \\
\text { accepted }\end{array}$ & $10.0 \%(n=16)$ & $18.8 \%(n=10)$ & $10.9 \%(n=5)$ \\
\hline 10.- $€$ & $42.8 \%(n=68)$ & $39.8 \%(n=45)$ & $52.2 \%(n=24)$ \\
\hline 20.- $€$ & $22.6 \%(n=36)$ & $23.0 \%(n=26)$ & $21.7 \%(n=10)$ \\
\hline 30.- $€$ & $8.8 \%(n=14)$ & $8.8 \%(n=10)$ & $8.7 \%(n=4)$ \\
\hline $\begin{array}{l}\text { Amount of } \\
\text { real income } \\
\text { loss }\end{array}$ & $15.7 \%(n=25)$ & $19.4 \%(n=22)$ & $6.5 \%(n=3)$ \\
\hline
\end{tabular}

\section{Discussion}

There are some restrictions within this pilot study. At first, there is always a bias in such voluntary explorations. Some kind of people always refuse to answer such questionnaires; inevitably only selective data are gathered. There is no realistic solution for this problem, because the answers have to be voluntarily. On the other hand, because anonymity was ensured, there is no cause to think that predominantly punctual patients participated. The representativeness of this 
study is limited to patients of Luebeck's vicinity.

181 questionnaires went into data analysis. The reference period included 2.779 appointments, average about 17 appointments per patient/year. Within these data occurred 87 totally missed and 12 heavy delays. $67.9 \%$ admitted never having missed an appointment with a doctor or therapists, $32.1 \%$ of the participants forgot dates or were delayed.

These German findings are below numbers of international studies. Lehmann et al. [14] in a Swiss clinic found 206 of 1.296 appointments have not been met. Okotie et al. [21] investigated 226 urological outpatients, $63.2 \%$ were punctual and $14.8 \%$ never came.

In regard to gender- and age-pattern, our data did not find any distinctions between timely patients and No-Shows. The predominant reason was "forgetfulness" and "confusion of dates".

We found low levels of missed rendezvous in accordance to severe pain and limitations in daily activities. This result is not amazing. The number of consultations of the missing/delayed group was nearly $50 \%$ higher than by the other patients, but the correlation coefficients revealed only a trend. Therefore the sheer quantity of visits only plays a minor role. People with severe pain and restrictions are still punctual under high numbers of appointments.

The non-employed cohort was significantly more failing/delaying. Not given is failing/delay with the employed group, although these are more occupied. Unemployed and retirees failed more often.

According to our study, patients who forget their appointments in the outpatient health care system, judge their memory as poor and are also forgetful about job-related and private appointments. Both groups of non-employed (job-seeking and pensioners) varied significantly compared with the employed group. Therefore there exist two groups of "persons of risk".

Satiani et al. [23] asked 8.766 patients about appointment reminders, only $53 \%$ agreed. Our study confirms skepticism towards reminders. $60 \%$ roughly did not want them, only $25 \%$ considered them as helpful. As rather helpful the reminders were judged from the group of forgetful patients. The majority (about 60\%) was willing to pay the max. of 1.$€$ for a reminder. Patients who already had forgottten an appointment did not agree to pay more for a reminder.

We asked exploratory for no-show fee-acceptance. Smoller et al. [24] found no standards whatsoever. Some institutions fail to respond; some ask for a surcharge, some notified exclusion of further treatment. $10 \%$ of our whole sample rejected such a charge, $42 \%$ considered a fee of 10 .- $€$ as appropriate, another $23 \% 20 .-€$ and $9 \%$ voted for $20 .-€$. $16 \%$ judged a charge according to the real loss of doctor's/therapist's income as fair. Highlighted is the underestimation of occurring losses due to No-Shows in the health care system. Many patients believe that No-Shows can always be filled up from a full waiting room. On the other hand quality management requires practitioners to provide appointments on schedule in order to avoid waiting time. Professional groups like psychotherapists don't have a waiting room for walk-in clients. Running expenses for rent, receptionists and equipment occur during idle times and are in Germany in no way covered by 10 .- $€$ or 20 .- $€$. Health insurances do not pay for not performed services. If not retrieving them from the patient, the doctor/therapist is left alone with his expenses. However, in most cases one never gets charges off patients who forgot their appointment. Legally the doctor/therapist is obliged to prove the appointment, which requires expanded management. This will hardly be performed by ambulatory institutions. There is even no chance to refuse making an appointment with patients who often have missed theirs before. A termination of treatment in the health care system collides with narrowly defined public service obligations, implicating compulsory treatment of an ailing person.

Practical conclusions: Most important take home message of this little pilot study is: Unemployed and retired patients seem to forget appointments more often. Data show that these patients are often aware of their memory deficits. It is too tedious to forward reminders to all patients, however consideration is worth to target "persons at risk". This could be performed while arranging the appointment. Following our conclusions a 1.- $€$ fee would be acceptable for most patients, particularly when impending a fine for „No-Show“.

\section{Acknowledgements}

We thank all patients who participated in this study. We thank David Reeves for his corrections in an earlier draft of this article.

\section{References}

[1] Barron WM. Failed appointments. Who misses them, why they are missed, and what can be done. Prim Care. 1980; 7: 563-574.

[2] Belardi FG, Weir S, Craig FW. A controlled trial of an advanced access appointment system in a residency family medicine center. Fam Med. 2004; 36(5): 341-345. I. S. Jacobs and C. P. Bean, "Fine particles, thin films and exchange anisotropy," in Magnetism, vol. III, G. T. Rado and H. Suhl, Eds. New York: Academic, 1963, pp. 271-350.

[3] Bigby J, Giblin J, Pappius EM, Goldman L. Appointment reminders to reduce no-show rate. JAMA. 1983; 250(13): 1742-1745.

[4] Bigby JA, Pappius E, Cook EF, Goldman L. Medical consequences of missed appointments. Arch Intern Med. 1984; 144(6): 1163-1166.

[5] Cashman SB, Savageau JA, Lemay CA, Ferguson W. Patient health status and appointment keeping in an urban community health center. J Health Care Poor Underserved. 2004; 15(3): 474-488.

[6] Gatrad AR. A completed audit to reduce hospital outpatients non-attendance rates. Arch Dis Childhood. 2000; 82: 59-61.

[7] Goldman L, Freidin R, Cook F, Eigner J, Grich P. A multivariate approach to the prediction of no-show behavior in a primary care center. Arch Intern Med. 1982; 142(3): 563-567. 
[8] Hagerman GA. Testing the mailed appointment reminder in family practice. J Fam Pract. 1978; 7(1): 199-201.

[9] Hashim MJ, Franks P, Fiscella K. Effectiveness of telephone reminders in improving rate of appointment kept at an outpatient clinic: A randomized controlled trial. J Am Board Fam Pract. 2001; 14(3): 193-196.

[10] Hurtado AV, Greenlick MR, Colombo TJ. Determinants of medical care utilization: Failure to keep appointments. Med Care. 1973; 11(6): 189-198.

[11] Izard T. Managing the habitual no-show patient. Fam Pract Manag. 2005; 12(2): 65-66.

[12] Johnson, B.J., Mold, J.W.\& Pontious, J.M. Reduction and Management of No-Shows by Family Medicine Residency Practice Exemplars. Annals of Family Medicine. 2007; 5: 534-539

[13] Lacy, N.L., Paulman, A., Reuter, M.D. \& Lovejoy, B. Why We Don't Come: Patient Perceptions on No-Shows. Annals of Family Medicine. 2004; 2: 541-545.

[14] Lehmann TN, Aebi A, Lehmann D, Balandraux Olivet M, Stalder H. Missed appointments at a Swiss university outpatient clinic. Public Health. 2007; 121(10): 790-799.

[15] Macharia WM, Leon G, Roewe BH, Stephenson BJ, Haynes RB. An overview of interventions to improve compliance with appointment keeping for medical services. JAMA. 1992; 267:1813-1817.

[16] Milne RG, Horne M, Torsney B. SMS reminders in the UK national health service: an evaluation of its impact on "no-shows" at hospital out-patient clinics. Health Care Manage Rev. 2006; 31(2): 130-136.
[17] Moore CG, Wilson-Witherspoon P, Probst JC. Time and money: effects of no-shows at a family practice residency clinic. Fam Med. 2001; 33: 522-527.

[18] Moser SE. Effectiveness of post card appointment reminders. Fam Pract Res J. 1994; 14: 281-288.

[19] Neal RD, Hussain-Gambles M, Allgar VL, Lawlor DA, Dempsey O. Reasons for and consequences of missed appointments in general practice in the UK: Questionnaire survey and prospective review of medical records. BMC Fam Pract. 2005; 6: 47.

[20] O'Brien G, Lazebnik R. Telephone call reminders and attendance in an adolescent clinic. Pediatrics. 1998; 101: e6.

[21] Okotie OT, Patel N, Gonzalez CM. The effect of patient arrival time on overall wait time and utilization of physician and examination room resources in the outpatient urology clinic. Adv Urol. 2008: 507436

[22] Quattlebaum TG, Darden PM, Sperry JB. Effectiveness of computer-generated appointment reminders. Pediatrics. 1991; 88(4): 801-805.

[23] Satiani B, Miller S, Patel D. No-show rates in the vascular laboratory: analysis and possible solutions. $J$ Vasc Interv Radiol. 2009; 20(1): 87-91.

[24] Smoller JW, McLean RY, Otto MW, Pollack MH. How do clinicians respond to patients who miss appointments? J Clin Psych. 1998; 59: 330-340.

[25] Vardy DA, Freud T, Shvartzman P, Sherf M, Spilberg O, Goldfarb D, Mor-Yosef S. Introducing co-payment for consultant specialist services. Isr Med Assoc J. 2006; 8(8): 558-562. 